\title{
Thunder Out of China
}

\author{
Yuri Deigin
}

$\mathrm{O}$ N AUgust 27, 2021, the Office of the Director of National Intelligence released a summary of the US Intelligence Community's assessment on the origins of COVID-19. ${ }^{1}$ Four of the agencies involved and the National Intelligence Council assessed "with low confidence that the initial SARS-CoV-2 infection was most likely caused by natural exposure to an animal infected with it or a close progenitor virus."

One of the agencies-later reported as the $\mathrm{FBI}^{3}-$ assessed "with moderate confidence that the first human infection with SARS-CoV-2 most likely was the result of a laboratory-associated incident, probably involving experimentation, animal handling, or sampling by the Wuhan Institute of Virology."

"These analysts," the summary continued, "give weight to the inherently risky nature of work on coronaviruses."

According to the World Health Organization (WHO), there have now been more than 360 million confirmed cases of COVID-19, resulting in over 5.6 million deaths worldwide. $^{5}$

Questions about the origins of COVID-19 are of more than academic interest.

$\mathrm{Z}$ OONOSIS IS CONSIDERED the default explanation for the outbreak of any new infectious disease. A number of pandemics occurred during the twentieth century, almost all of them of zoonotic origin. The one known exception is the 1977 H1N1 flu pandemic, which was caused by an insufficiently attenuated vaccine candidate that escaped either from a laboratory or from clinical trials. ${ }^{6}$

A number of disease outbreaks began in Southeast Asia following zoonotic jumps: the Asian flu pandemic (1957), which originated in China; the Hong Kong flu pandemic (1967); and the avian flu outbreak (2005), which was first reported in Vietnam. The first SARS (severe acute respiratory syndrome) coronavirus outbreak began in China during 2002 and infected more than 8,000 people worldwide between 2002 and 2003, as well as dozens more people in 2004 after several laboratory leaks.

In a 2007 paper for Clinical Microbiology Reviews, a team of virologists from the University of Hong Kong issued a clear warning:
The presence of a large reservoir of SARS-CoV-like viruses in horseshoe bats, together with the culture of eating exotic mammals in southern China, is a time bomb. The possibility of the reemergence of SARS and other novel viruses from animals or laboratories and therefore the need for preparedness should not be ignored.?

Horseshoe bats, the genus Rhinolophus, are the natural reservoir for hundreds of coronavirus strains closely related to the SARS virus. ${ }^{8}$

Once the SARS-CoV-2 outbreak had begun, virologists quickly reached the conclusion that the pandemic was almost certainly of natural origin. In February of 2020, barely a month after the SARS-CoV-2 genome was released, a team led by Kristian Andersen, an immunologist at the Scripps Research Institute in California, published a preprint and then a paper in Nature Medicine entitled "The Proximal Origin of SARS-CoV-2." If SARS$\mathrm{CoV}-2$ had been designed, they argued, it could have been designed better, and since it was not designed better, it most likely was not designed. "While the analyses ... suggest that SARS-CoV-2 may bind human ACE2 with high affinity," the Nature Medicine paper noted, "computational analyses predict that the interaction is not ideal and that the RBD [receptor-binding domain] sequence is different from those shown in SARS-CoV to be optimal for receptor binding." "The high-affinity binding of the SARS-CoV-2 spike protein to human ACE2," the authors concluded,

is most likely the result of natural selection on a human or human-like ACE2 that permits another optimal binding solution to arise. This is strong evidence that SARS-CoV-2 is not the product of purposeful manipulation [emphasis added]..$^{10}$

A month before Nature Medicine issued the paper by Andersen et al., The Lancet published a letter signed by 27 leading virologists dismissing the hypothesis that the virus originated in a laboratory:

The rapid, open, and transparent sharing of data on this outbreak is now being threatened by rumors and misinformation around its origins. We stand together to strongly 
condemn conspiracy theories suggesting that COVID-19 does not have a natural origin. ${ }^{11}$

One of the authors of the letter was Peter Daszak, the president of EcoHealth Alliance, a US-based nonprofit NGO. Since 2004, EcoHealth had been collaborating with the Wuhan Institute of Virology (WIV) on studies of coronaviruses in bats. ${ }^{12}$ The relationship between EcoHealth and the WIV was close. A specialist in the transmission of infectious diseases among animals, Daszak was frequently listed as a coauthor on their papers, often alongside the director of the WIV's Center for Emerging Infectious Diseases, Shi Zhengli. ${ }^{13}$

The authors of the letter that appeared in The Lancet, Daszak among them, declared that they had reached their conclusions while holding no competing interests. It was not until 16 months later that the journal issued a demurral with respect to Daszak's declaration. He updated his statement to clarify his employment at EcoHealth and the nature of EcoHealth's research in China, and to affirm that their "work in China was previously funded by the US National Institutes of Health (NIH) and the United States Agency for International Development (USAID).”14 Daszak's updated disclosure does not include any mention of the WIV, instead referring to EcoHealth's “collaboration with a range of universities and governmental health and environmental science organisations."

On January 14, 2021, a multidisciplinary team of international experts, Daszak among them, traveled to Wuhan to investigate the origins of the virus on behalf of the WHO. ${ }^{15}$ The study lasted 28 days. The WHO team was given a guided tour of the WIV facilities and they were able to interview some of its scientists. The "introduction [of the virus] through a laboratory incident," the WHO concluded, "was considered to be an extremely unlikely pathway." Instead, they argued, "introduction through an intermediate host is considered to be a likely to very likely pathway."17 Elsewhere in their report, the WHO team repeated assurances they had received during their time in China:

The Wuhan CDC [Center for Disease Control and Prevention] lab which moved on $2^{\text {nd }}$ December 2019 [to a new location near the Huanan market] reported no disruptions or incidents caused by the move. They also reported no storage nor laboratory activities on CoVs or other bat viruses preceding the outbreak. ${ }^{18}$

If, in February of 2021, the WHO's team of experts were prepared to take the WIV scientists at their word, by August of 2021, some of them confessed to having had reservations all along. In an interview for a Danish television documentary, Peter Ben Embarek, the leader of the WHO team, admitted that Chinese officials had pressured them to drop the laboratory leak hypothesis. "In the beginning, they didn't want anything about the lab [in the WHO report], because it was impossible, so there was no need to waste time on that," Ben Embarek remarked. "We insisted on including it," he continued, "because it was part of the whole issue about where the virus originated." 19 Ben Embarek added that there were scenarios under which the laboratory leak hypothesis could be consistent with the assumption that COVID-19 had an animal origin:

A lab employee infected in the field while collecting samples in a bat cave-such a scenario belongs both [emphasis added] as a lab-leak hypothesis and as our first hypothesis of direct infection from bat to human. We've seen that hypothesis as a likely hypothesis. 20

When questioned about the interview by the Washington Post, Ben Embarek initially claimed his remarks had been mistranslated before declining to comment further. ${ }^{21}$ But Ben Embarek was not the only one expressing reservations. A month earlier, the WHO's director-general, Tedros Adhanom Ghebreyesus, conceded during a press conference that there had been a "premature push" to rule out the laboratory leak hypothesis-comments that contradicted the conclusions of the WHO's own report, released just a few months beforehand. ${ }^{22} \mathrm{He}$ called on China to allow a full audit of the Wuhan laboratories. ${ }^{23}$ "I was a lab technician myself, I'm an immunologist, and I have worked in the lab, and lab accidents happen," Tedros remarked. "It's common." 24

As it turned out, Tedros had every reason to express caution. To date, nearly 82,000 animal samples have been tested in China for SARS-CoV-2. No intermediate animal host has been identified in Wuhan or anywhere else in the country. ${ }^{25}$

NTHONY FAUCI HAS been the director of the US
National Institute of Allergy and Infectious Dis-
eases (NIAID) since 1984. Over the last few decades, he has expressed his support for gain-of-function research on numerous occasions. In a 2011 op-ed for the Washington Post co-authored with Francis Collins, the director of the NIH between 1993 and 2019, they made the case for viruses "engineered in isolated biocontainment laboratories" as a means to identify "genetic pathways by which such a virus could better adapt to transmission among people." 26 The benefits were not elaborated in detail, the authors simply noting that, "important information and insights can come from generating a potentially dangerous virus in the laboratory." The op-ed concludes with a brief consideration of the risks involved.

The following year Fauci published a paper entitled "Research on Highly Pathogenic H5N1 Influenza Virus: The Way Forward," again making the case for gain-of-function research. ${ }^{27}$ In his commentary, Fauci acknowledges the question of whether "knowledge obtained from these experiments could inadvertently affect public health in an adverse way, even in nations multiple time zones away."28 
He then invites the reader to consider a hypothetical scenario concerning "an important gain-of-function experiment involving a virus with serious pandemic potential ... performed in a well-regulated, world-class laboratory by experienced investigators." The information gleaned from the study is then "used by another scientist who does not have the same training and facilities and is not subject to the same regulations."

In an unlikely but conceivable turn of events, what if that scientist becomes infected with the virus, which leads to an outbreak and ultimately triggers a pandemic? Many ask reasonable questions: given the possibility of such a scenario-however remote-should the initial experiments have been performed and/or published in the first place, and what were the processes involved in this decision?

\section{Fauci's answer is unequivocal:}

Scientists working in this field might say-as indeed I have said-that the benefits of such experiments and the resulting knowledge outweigh the risks [emphasis added]. It is more likely that a pandemic would occur in nature, and the need to stay ahead of such a threat is a primary reason for performing an experiment that might appear to be risky.

In his conclusion, Fauci acknowledges "genuine and legitimate concerns about this type of research," but his message remains clear: the research is worthwhile and important.

Of course, no amount of gain-of-function research has helped the world to "stay ahead" of the COVID-19 pandemic, nor can any advocate of virological gain-of-function research explain exactly how one can stay ahead of nature.

At the end of 2012, Fauci spoke at a workshop on gainof-function research on HPAI H5N1 viruses hosted by the NIH. "There's disagreements to the scientific and/or public health value of these experiments," he remarked in a section of his presentation that discussed funding guidelines, "but I believe people who feel they shouldn't be conducted are in the minority."29

During Fauci's tenure at NIAID, the NIH funded numerous studies involving coronaviruses and gain-of-function research. In 2015, the NIH supported a study led by Ralph Baric, a virologist from the University of North Carolina at Chapel Hill, and the WIV's Shi. Published in Nature Medicine, their paper described the creation of a chimera, the result of a spike protein gene from a bat coronavirus being pasted into a mouse-adapted SARS virus. ${ }^{30}$

The completion of this study was only possible after Baric received an exemption for his research from NIH officials. ${ }^{31}$ In October 2014, the White House Office of Science and Technology instituted a pause in new funding for gain-of-function research after a series of "biosafety incidents at Federal research facilities." ${ }^{32}$ They also recommended "those currently conducting this type of work, whether federally funded or not, to voluntarily pause their research while risks and benefits are being reassessed." Baric wrote to the NIH's biosecurity board to plead his case and an exemption was granted. ${ }^{33}$

Three years later, following the election of Donald Trump, Fauci played a key role in the NIH's decision to resume gain-of-function research. ${ }^{34}$ The NIH funded a new study that expanded on the WIV's 2015 work with Baric, creating eight novel chimeric coronaviruses. ${ }^{35}$ When the 2019 SARS-CoV-2 outbreak occurred, work at the WIV was underway on further research, under yet another round of funding. ${ }^{36}$

In his May 2021 US Senate hearing, Fauci claimed that the NIH-funded research at the WIV did not constitute gain-of-function research. ${ }^{37} \mathrm{He}$ was emphatic in his denial because his memory was defective in its scope. In a February 2020 email that Fauci sent to his subordinates, obtained under the Freedom of Information Act (FOIA), an attached PDF of the Baric and Shi paper was labeled "SARS Gain of Function." 38

$\mathrm{F}$ AUCI HAD AT HIS command virologists willing to offer him their advice. Kristian Andersen was among them. Having consulted with his colleagues, Andersen sent Fauci an email on February 1, 2020-also obtained under the FOIA-in which he claimed that the SARS-CoV-2 genome looked engineered, and, what is more, that its genome was "inconsistent with expectations from evolutionary theory." ${ }^{39}$ Within hours, Fauci held a teleconference with Andersen, Sir Jeremy Farrar, director of the Wellcome Trust, Collins, and several other virologists. ${ }^{40}$

A June 2021 article by USA Today reported that, "details of what was said in the meeting, including extensive notes taken by one participant and further thoughts shared by others, were blacked out by the NIH before the emails were made public." ${ }^{41}$ Interviewed for the same article, Fauci recalled:

"It was a very productive back-and-forth conversation where some on the call felt it could possibly be an engineered virus" ... Others, [Fauci] said, felt the evidence was "heavily weighted" toward the virus emerging from an animal host. ${ }^{42}$

Although the details of the conversation remain opaque, when the preprint of Andersen's "Proximal Origin" paper appeared several weeks later, what had before looked engineered now looked natural. ${ }^{43}$

When the Fauci emails were published in June 2021, ${ }^{44}$ the shifts in Andersen's views were greeted with consternation. It had been the WIV's release of the genome for a viral strain called RaTG13, Andersen later explained, that had changed his mind. ${ }^{45}$ Curiously enough, Andersen had tweeted about RaTG13 a week before writing his initial email to Fauci. ${ }^{46}$ Rather than attempting to resolve 
all these inconsistencies when they were pointed out to him, Andersen instead chose to first delete the offending tweets, and then to delete his Twitter account altogether. ${ }^{47}$

According to Andersen's senior colleague, Farrar, other coauthors of the "Proximal Origin" paper were initially even more convinced the virus originated in a laboratory. Farrar later described the events surrounding the meeting with Fauci, Collins, Andersen, et al., in his book Spike: The Virus vs. The People. ${ }^{48}$ That account was the subject of a mid-2021 article by Unherd:

Before the call on 1 February, Farrar says Andersen was "60 to $70 \%$ " convinced the virus came from a lab, while Australian virologist Eddie Holmes was " $80 \%$ sure this thing had come out of a lab." Patrick Vallance, Britain's chief scientific officer who joined the call, tipped off intelligence agencies about their concerns. But others on the hour-long call argued the new virus "was more convincingly explained, scientifically, as a natural spillover than a laboratory event." Afterwards, the participants swapped notes but Farrar remained torn on the origins. "On a spectrum if 0 is nature and 100 is release I am honestly at 50," he emailed Fauci. "My guess is this will remain grey unless there is access to the Wuhan lab-and I suspect that is unlikely." ${ }^{49}$

The emails obtained under the FOIA revealed that, three days after the call with Fauci, Andersen and Baric assisted Daszak in drafting the letter that subsequently appeared in The Lancet denouncing what, in an email, Andersen would call the "crackpot" and "fringe" hypotheses that SARS-CoV-2 was engineered. ${ }^{50}$

The following day, Farrar emailed Fauci and Collins again. ${ }^{51}$ In his message, Farrar reported having convinced the WHO to form a group that would look at the origins of SARS-CoV-2. He also informed Fauci and Collins that the WHO had asked for "names to sit on that Group" and requested that the pair "please do send any names." Farrar proposed a subsequent meeting to "frame the work of the group" and suggested there would be "pressure on this group from your and our teams next week."

The emails also reveal that having helped draft the Lancet letter, Baric and Daszak-initially at least-opted not to sign it. ${ }^{52}$ Baric expressed concern that if he were to sign the letter it might look "self-serving, and we lose impact." Daszak, on the other hand, sought to downplay his own involvement, along with that of Baric and another virologist, Linfa Wang. "You, me, and him should not sign this statement," Daszak suggested to Baric and Wang, "so that it has some distance from us and therefore doesn't work in a counterproductive way."

"We'll then put it out in a way that doesn't link it back to our collaboration so we maximize an independent voice." first observed in Wuhan, the initial outbreak occurring between October and December of
2019. The hypothesis that SARS-CoV-2 originated elsewhere and traveled undetected until it reached Wuhan is implausible. Earlier transmission would have led to earlier outbreaks in other locations, or would have produced viral lineages at earlier spots on the SARS-CoV-2's phylogenetic tree. The virus phylogeny is strongly rooted in Wuhan..$^{53}$

While there is little doubt that SARS-CoV-2 originated in Wuhan, questions remain about where in Wuhan it originated. After the 2002 SARS outbreak in Guangdong, the first SARS patients had almost immediately been traced to restaurant workers handling exotic animals: palm civets sold at a local market were, within weeks, identified as an intermediate host. ${ }^{54}$

In November of 2021, the virologist Michael Worobey, writing in Science, argued that the SARS-CoV-2 outbreak originated in the Huanan Seafood Market in Wuhan..$^{55}$ In an interview with University of Arizona News, Worobey remarked that the evidence was like a "flashing red arrow pointing to the Huanan market as by far the most likely site of origin, with a failure to put a stop to sales of illegal wildlife in markets like Huanan as the reason.,56

Worobey's article, it should be noted, provided no new evidence for zoonosis and his conclusion was based solely on a reanalysis of Wuhan patient data from December 2019. The data were subsequently shown to be erroneous. ${ }^{57}$ The "strong evidence" for zoonosis cited by Worobey in his article for Science amounted to nothing more than conjecture: "[T] hat most early symptomatic cases were linked to Huanan Market-specifically to the western section (1) where raccoon dogs were caged (2)-provides strong evidence of a live-animal market origin of the pandemic." ${ }^{58}$ Not a single racoon dog has yet been found carrying a progenitor of SARS-CoV-2, nor has any other animal been infected by such a progenitor. Around 82,000 animal samples have now been analyzed in China, including 1,700 recent wildlife trade samples sold in wet markets. ${ }^{59}$ All were negative for any SARS-like virus.

Whether the outbreak originated in a female seafood vendor at the Huanan Market remains unclear. But the market itself clearly served as an epidemiological hot spot, harboring what Worobey described as a "genuine preponderance of early COVID-19 cases." ${ }^{\circ 0}$ While some early human cases were, indeed, linked to the Huanan Market, many cases predated the market outbreak. ${ }^{61}$ Moreover, the SARS-CoV-2 strains circulating in the market were not ancestral, all of them carrying three novel mutations not seen in earlier patients. ${ }^{62}$ Nor is Wuhan home to the horseshoe bats known to carry SARS-like viruses. Indeed, the likelihood of a bat virus outbreak in Wuhan was deemed so small that in 2018 the city was used as a negative control for a study by the WIV that assessed the risk of zoonotic jumps of SARS-like viruses in Yunnan from bats to people who lived within one to six kilometers of such bats. ${ }^{63}$ The study found that six of 218 farmers carried antibodies to the bat SARS-like virus called Rp3, in contrast to none 
of the 240 residents of Wuhan. Both Daszak and Shi are listed among the sixteen coauthors for the study.

After the SARS-CoV-2 outbreak broke out, Daszak cited this study in a tweet to estimate the general incidence of coronavirus zoonotic spillovers.

These jumps occur every day. We conducted sero-surveys in SE Asia \& found $3 \%$ of rural people have antibodies to bat CoVs. That means 1-7 million people per year exposed to bat origin SARS-related CoVs. It's utterly illogical to think that this did not lead to the current outbreak. ${ }^{64}$

If 218 residents of rural Yunnan living in proximity to bat caves showed a $3 \%$ rate of seropositivity, then by extrapolation, he argued, one to seven million people in rural Southeast Asia should be exposed to some SARS-related coronavirus every year. It was certainly a curious argument for someone in Daszak's position to make.

By contrast, Shi acknowledged that Wuhan is an unlikely place for a SARS-like virus to emerge. She addressed the topic in a 2020 interview with Scientific American:

"I had never expected this kind of thing to happen in Wuhan, in central China," [Shi] remarked. Her studies had shown that the southern, subtropical provinces of Guangdong, Guangxi, and Yunnan have the greatest risk of coronaviruses jumping to humans from animals-particularly bats, a known reservoir. If coronaviruses were the culprit, she remembers thinking, "Could they have come from our lab?"65

I N 2019, ECOHEALTH WAS scheduled to receive another round of funding from the NIH for project 2R01AI110964-06, "Understanding the Risk of Bat Coronavirus Emergence." ${ }^{\circ 6}$ This grant, the umbrella project that had funded EcoHealth's collaboration with the WIV since 2014, had been initiated with three broad aims. The first was to " $[c]$ haracterize the diversity and distribution of high spillover-risk SARSr-CoVs in bats in southern China," while the second involved "[c]ommunity, and clinic-based syndromic, surveillance to capture SARSr-CoV spillover, routes of exposure and potential public health consequences." The third aim was much more explicit about what the researchers had in mind:

In vitro and in vivo characterization of SARSr-CoV spillover risk, coupled with spatial and phylogenetic analyses to identify the regions and viruses of public health concern. We will use S protein sequence data, infectious clone technology, in vitro and in vivo infection experiments and analysis of receptor binding to test the hypothesis that \% divergence thresholds in $\mathrm{S}$ protein sequences predict spillover potential. ${ }^{67}$

Prior to the cancellation of the NIH grant in April $2020{ }^{68}$ EcoHealth received US\$3.1M in funding for the project. ${ }^{69}$ Of that amount, US $\$ 600,000$ was passed on to the WIV. ${ }^{70}$

In a December 2018 paper for Nature Reviews Microbiology, researchers from the WIV outlined their vision for the next stages of the project:

[F]uture work should be focused on the biological properties of [SARS-like and MERS (Middle East Respiratory Syndrome)-like] viruses using virus isolation, reverse genetics and in vitro and in vivo infection assays. The resulting data would help the prevention and control of emerging SARS-like or MERS-like diseases in the future. ${ }^{71}$

The ultimate goal of such work may have been to create a pan-coronavirus vaccine. Research focused on SARS-like and MERS-like viruses was a stated goal not just for WIV, but for EcoHealth as well. Daszak said as much publicly in a November 2019 interview:

You can manipulate [coronaviruses] in the lab pretty easily, it is the spike protein drives a lot of what happens with the coronavirus zoonotic risk. You can get the sequence, you can build the protein. We worked with Ralph Baric at UNC who did this, insert into a backbone of another virus and do some work in the lab. So, you can get more predictive when you find a sequence. ... The logical progression for vaccines - if you are going to develop a vaccine for SARS, people are going to use pandemic SARS, but let's try to insert some of these [other spike genes] and get a better vaccine. ${ }^{72}$

In addition to sub-grants from EcoHealth, research at the WIV was supported by Chinese funding. Ben $\mathrm{Hu}$, a researcher at the WIV, was awarded a three-year grant from the Youth Science Fund for a project to investigate "Pathogenicity of Two New Bat SARS-Related Coronaviruses to Transgenic Mice Expressing Human ACE2 Receptor., ${ }^{\prime 3} \mathrm{Hu}$ has been a member of Shi's group at the WIV since $20155^{74}$

The WIV undertook its work for the best of reasons. Prior to the emergence of SARS-CoV-2, it was widely held among researchers that a future epidemic, or Disease $\mathrm{X}$ as the WHO termed it, might be caused by a coronavirus. ${ }^{75}$ In June 2020, Shi and her colleague Shibo Jiang published a paper entitled "The First Disease X Is Caused by a Highly Transmissible Acute Respiratory Syndrome Coronavirus."76 "Disease X," Shi and Jiang observed, "would be a new disease with an epidemic or pandemic potential caused by an unknown pathogen." Unknown? Not quite. "[T]he first Disease X," they wrote, "could be a transmissible infectious disease caused by a novel coronavirus originated from bats."

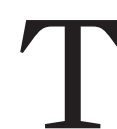

HE VIRUS SARS-CoV-2 contains a number of curious genomic features-its novel furin cleavage site most obviously. No other known SARS-related coronavirus has a furin cleavage site. To enter human 
cells, SARS-CoV-2 uses a spike protein that attaches to human ACE2 receptors. The protein must then be cut by an enzyme in order to fuse with the cell membrane and penetrate the cell. The spike protein consists of two parts, S1 and S2. S1 is responsible for primary contact with the receptor, and $\mathrm{S} 2$, for fusion and penetration. For $\mathrm{S} 2$ to initiate fusion, the $\mathrm{S} 1 / \mathrm{S} 2$ junction must be cut by a host enzyme like furin or TMPRSS2. This junction is where the novel furin cleavage site is found in SARS-CoV-2. Furin is a very efficient enzyme, found both on the surface and in the interior of many human cells, most notably in the airway epithelium. It is furin's presence in the interior of the cell that allows newly formed virions to emerge in a pre-cut conformation, enhancing their infectivity.

The furin cleavage site in SARS-CoV-2 was created by a peculiar 12-nucleotide insertion-so peculiar, in fact, that the genomic locus in SARS-CoV-2 enveloping its furin cleavage site is, at least, twelve nucleotides longer than any of its relatives. ${ }^{77}$ Virologists have created novel furin cleavage sites in coronaviruses repeatedly. ${ }^{78}$ It is obvious why. ${ }^{79}$ Furin cleavage sites greatly expand both the tissue and species tropism of a virus..$^{80}$ And furin cleavage sites enhance the adaptation of a viral strain to certain cell lines.

The WIV failed to mention the novel furin insertion in its first two papers on SARS-CoV-2, ${ }^{81}$ even though the WIV had in its possession the closest relative of SARS-CoV-2 at that time-the strain RaTG13. ${ }^{82}$ Genomic comparison made the furin cleavage site obvious. In their diagram comparing the two genomes, the WIV cut off the comparison just before the novel insertion. In the paper that first mentioned RaTG13, the WIV researchers did not explain where RaTG13 came from or how they came to possess it.

The novel insertion is comprised of the nucleotides $\mathrm{T}$ CCT CGG CGG GC; the corresponding amino acids are proline (CCT) arginine (CGG) arginine (CGG) alanine (GCA) - or PRRA in one-letter amino acid notation. The nucleotide insertion is odd because it is not completely in frame, the insertion splitting the ancestral serine codon TCA while preserving the downstream frame..$^{83}$ Odd as well are the two repeating CGG arginine codons. CGG is the rarest of the six codons to code for arginine in bat coronaviruses, and the SARS-CoV-2 insertion is the only example in which two CGG codons are consecutive. In fact, the CGG-CGG doublet is the only one coding for two arginines in all 255 SARS-like viruses with protein annotations listed in the NIH Genetic Sequence Database (GenBank). ${ }^{84}$

In contrast to bat coronaviruses, CGG is the most frequent arginine codon in humans.

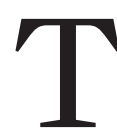

HE VIRUS RaTG13 is SARS-like and belongs to the family of beta-coronaviruses. It is a close relative of SARS-CoV-2. Having obtained the SARS-CoV2's genome on December 27, 2019, ${ }^{85}$ the WIV would have been in a position to see that it matched RaTG13 by $96.2 \%$. The WIV announced they had RaTG13 in their possession in a preprint uploaded to bioRxiv on January 23, 2020, and shortly thereafter published in Nature.$^{86}$ Their explanation was terse:

We then found that a short region of RNA-dependent RNA polymerase (RdRp) from a bat coronavirus (BatCoV RaTG13)-which was previously detected in Rhinolophus affinis from Yunnan province-showed high sequence identity to 2019-nCoV. We carried out full-length sequencing on this RNA sample. ${ }^{87}$

This suggests that WIV researchers first detected a match between SARS-CoV-2 and a short RdRp fragment of RaTG13. With the match in hand, they were then led to fully sequence RaTG13. After the WIV was forced to release raw sequencing data, it was noted that they contained amplicons of 2017 and $2018 .^{88}$

When had RaTG13 been sequenced?

In 2018, as the WIV later admitted. ${ }^{89}$

It was a compromising admission. No match between the RdRp fragment and SARS-CoV-2 was needed in order to establish a match between RaTG13 and SARS-CoV-2. The WIV already had the full RaTG13 genome: it would have shown up as the top match to SARS-CoV-2.

But there was another important aspect of RaTG13's history that the WIV failed to disclose: the fact that it had been collected in 2012 from a mine in Mojiang, a county in the south of Yunnan province. That year six miners contracted viral pneumonia while working in the mine, and three of them later died. ${ }^{90}$ The WIV was subsequently invited to analyze tissue samples from the miners. They found SARS-reacting IgG antibodies..$^{91}$ Over the next several years, researchers from the WIV visited the Mojiang mine several times looking for new viruses. The WIV eventually acknowledged these details in an addendum published nine months after the Nature paper..$^{92}$ In the same addendum, the WIV claimed that RaTG13 is identical to a sample labelled Ra4991, which was first mentioned in a 2016 paper, ${ }^{93}$ and whose 370-nt RdRp fragment was deposited with GenBank at the time. ${ }^{94}$

The WIV also neglected to mention the novel furin cleavage site in SARS-CoV-2: it would have been immediately apparent to any trained coronavirologist looking at the alignment of spike proteins in SARS-CoV-2 and RaTG13. In their paper disclosing RaTG13, ${ }^{95}$ the WIV chose to cut off that alignment just before the novel furin cleavage site. Days before coauthoring that paper, Shi coauthored another paper, this time with Jiang, on SARSCoV-2 that correctly identified the site of SARS-CoV-2's $\mathrm{S} 1 / \mathrm{S} 2$ cleavage at the RRAR|S novel cleavage site. ${ }^{96}$

It is hard to believe that experts such as Shi or Jiang could have missed the novel furin cleavage site at the S1/S2 cleavage junction-while specifically performing their alignment in the search for the $\mathrm{S} 1 / \mathrm{S} 2$ cleavage site of SARS-CoV-2. It seems Shi missed it twice. The Nature alignment used the corrected amino acid numbering of SARS-CoV-2's spike, whereas the Jiang paper used the 
uncorrected numbering: the WIV initially erroneously included nine extra amino acids in SARS-CoV-2's spike protein sequence they uploaded to GenBank. ${ }^{97}$ Thus, the proper S1/S2 SARS-CoV-2 cleavage locus is R685/S686 and not R694/S695. Another researcher who presumably missed the novel furin cleavage site was $\mathrm{Ben} \mathrm{Hu}$, who was acknowledged in the Jiang and Shi paper for his work on "phylogenetic analysis of 2019-nCoV S gene." 98

RaTG13 itself remains somewhat mysterious. Its receptor-binding domain does not bind to any bat ACE2 receptor studied. A recent study tested the ACE2 receptor from the very bat species RaTG13 was allegedly sampled from, $R$. affinis. ${ }^{99}$ It found that RaTG13 is bad at binding to $R$. affinis ACE2. Even the T403R spike mutation, which was observed to make it bind well to human ACE2, was helpless when it came to R. affinis ACE2 binding.

By contrast, RaTG13 binds very well to human ACE2, and binds best of all to rat and mouse ACE2 receptors. Using the cited study's metric of the number of infected cells per well, RaTG13 was only about half as effective as SARS-CoV-2 at binding to the human ACE2 receptor (100k cells/well), and about eight times better than the effectiveness of SARS-CoV-2 using the $R$. affinis bat ACE2 ( $12 \mathrm{k}$ cells/well).

These findings suggest that RaTG13 might not be the original bat virus but could instead be the result of significant serial passaging of a bat virus in human cells or in mice ${ }^{100}$-which is where it could have encountered selective pressure to optimize its binding to both human and rodent $\mathrm{ACE} 2$ receptors. The WIV definitely sampled some SARS-like coronavirus from a mine in Mojiang, which they originally called Ra4991. This name first appeared in print in a 2014 master's thesis by Ning Wang, written under Shi's supervision. ${ }^{101}$ As part of his thesis, Wang amplified the $\mathrm{N}$ gene for a number of bat coronaviruses, Ra4991 being among them. Ra4991 was then briefly mentioned in a 2016 WIV paper as a novel SARS-related strain. ${ }^{102} \mathrm{~A}$ 370-nucleotide fragment of its RdRp gene was deposited with GenBank. ${ }^{103}$ In 2019, a WIV master's thesis by Yu Ping, co-supervised by Shi, described Ra4991 as having been fully sequenced, along with three other SARS-like coronaviruses. ${ }^{104}$ Those genomes were never made public.

It is unclear why RaTG13 had to be renamed in early 2020 if it was completely acceptable to keep calling it Ra4991 in 2019. Renaming viral sequences is quite rare in coronavirology and renaming something without referencing its previously published name is unheard of. In a Q\&A published by Science in July $2020,{ }^{105}$ Shi provided the following explanation:

Ra4991 is the ID for a bat sample while RaTG13 is the ID for the coronavirus detected in the sample. We changed the name as we wanted it to reflect the time and location for the sample collection. 13 means it was collected in 2013, and TG is the abbreviation of Tongguan town, the location where the sample was collected. ${ }^{106}$
For a sample attributed to a bat fecal swab, the metagenome of RaTG13's sequencing data contains an uncharacteristically low number of bacterial reads. ${ }^{107}$ Just $0.65 \%$ of the total reads belong to bacteria. By comparison, another WIV fecal swab sample from $R$. affinis (SRR11085736), which was uploaded to GenBank on the same day as RaTG13, contained $91 \%$ bacterial reads. The metagenomic profile of RaTG13 raw data is more consistent with a cultured sample.

In the same Q\&A with Science, Shi claimed that the original RaTG13 sample is no longer available for external verification.

As the sample [RaTG13] was used many times for the purpose of viral nucleic acid extraction, there was no more sample after we finished genome sequencing, and we did not do virus isolation and other studies on it. ${ }^{108}$

This claim is not only extremely troubling given all of its peculiarities, but is plainly inconsistent with a cultured sample-that is, one that scientists have managed to get to self-propagate in a cell culture indefinitely.

$\mathrm{S}$ EVERAL LAB LEAKS are known to have occurred over the past forty years. In November 2019, just prior to the current pandemic, an outbreak of brucellosis was traced to two labs in Lanzhou in northwest China. ${ }^{109}$ Around 100 students and staff were initially infected, that number eventually growing to 10,528 confirmed infections.

The deadliest pandemic of past years was the so-called Russian flu outbreak of 1977 , which was first detected among children in China. ${ }^{110}$ Today, the scientific consensus is that the outbreak came about through either a lab leak or a clinical trial of an insufficiently attenuated vaccine. ${ }^{111}$

The ensuing pandemic killed 700,000 people. ${ }^{112}$

In 1979, there was an anthrax leak from a laboratory in Sverdlovsk, Russia, which killed 66 people. ${ }^{113}$ The first SARS virus has also escaped from laboratories on at least four occasions: in 2003 in Singapore, in December 2003 in Taiwan, and twice in the spring of 2004 in China. ${ }^{14}$

Outsider auditors raised concerns about safety at the WIV as early as 2018. ${ }^{115}$ That year, US Embassy officials visited the institute and conducted several interviews with researchers, including Shi. After their visit, the diplomats dispatched cables to Washington outlining their concerns about inadequate safety controls. "During interactions with scientists at the WIV laboratory," one of the cables reported, "[the officials] noted the new lab has a serious shortage of appropriately trained technicians and investigators needed to safely operate this high-containment laboratory."116

Concerns about the risks associated with operating research laboratories were shared by the Chinese government. In January 2019, China's state news agency Xinhua reported that the Ministry of Education had ordered "a nationwide safety overhaul at higher education institutions' laboratories": 
Universities were asked to have around-the-clock and allaround control over laboratory hazards and risks during procurement, transportation, storage and use of dangerous goods and hazardous substances and waste disposal, according to a notice issued by the ministry. ${ }^{117}$

Soon after the COVID-19 outbreak, in February 2020, the novel SARS-CoV-2 virus was reported to have infected lab personnel in China, ${ }^{118}$ although these reports were subsequently denied. In November 2021, a confirmed SARS-CoV-2 lab leak in Taiwan led to 110 people being exposed to the virus by a single infected BSL-3 lab worker. ${ }^{119}$

Among the numerous changes observed on the WIV website since the COVID-19 outbreak in recent years, one of the most noticeable was the removal of a page that listed bat coronaviruses as BSL-2 pathogens. ${ }^{120}$ The BSL designation signifies compliance with four levels of "standard microbiological practices, special practices, safety equipment, and laboratory facilities" for "activities involving infectious microorganisms, toxins, and laboratory animals," defined by the Centers for Disease Control and Prevention. ${ }^{121}$ As part of her Science Q\&A, Shi confirmed that "coronavirus research in our laboratory is conducted in BSL-2 or BSL-3 laboratories."122 The critical differences between BSL-2 and BSL-3 were outlined in an article published by the MIT Technology Review:

BSL-2 is for moderately hazardous pathogens ... and relatively mild interventions are indicated: close the door, wear eye protection, dispose of waste materials in an autoclave. BSL-3 is for pathogens that can cause serious disease through respiratory transmission, such as influenza and SARS, and the associated protocols include multiple barriers to escape. Labs are walled off by two sets of self-closing, locking doors; air is filtered; personnel use full PPE [personal protective equipment] and N95 masks and are under medical surveillance. ${ }^{123}$

In sharp contrast to the WIV, Baric's research on constructing novel chimeric coronaviruses was undertaken in enhanced BSL-3 conditions with "additional steps like Tyvek suits, double gloves, and powered-air respirators for all workers." 124 The precautions did not stop there. "All workers," the MIT Technology Review reported, "were monitored for infections, and local hospitals had procedures in place to handle incoming scientists. It was probably one of the safest BSL-3 facilities in the world." 125 But even with all these precautions in place, the risks were unavoidable: "That still wasn't enough to prevent a handful of errors over the years: some scientists were even bitten by virus-carrying mice. But no infections resulted." ${ }^{26}$

In May 2021, the Wall Street Journal broke a story that, according to a previously undisclosed US intelligence report, three WIV researchers were hospitalized in November 2019, "with symptoms consistent with both
COVID-19 and common seasonal illness." ${ }^{127}$ While Chinese authorities maintain that first cases of SARS-CoV-2 are only known to have occurred in December, there is at least one report that the first case was recorded on November $17,2019 .^{128}$

I N MARCH 2018, EcoHealth and the WIV submitted a grant proposal to the Defense Advanced Research Projects Agency (DARPA) for their Preventing Emerging Pathogenic Threats program. ${ }^{129}$ The proposal was entitled "Project DEFUSE: Defusing the Threat of BatBorne Coronaviruses.” It outlined a massive US\$14 million research program that included collecting thousands of viral samples in bat caves in Yunnan to identify high-risk strains with the ultimate goal of immunizing bats against them. Most intriguingly, the proposal revealed intentions to genetically engineer novel cleavage sites in the spike gene of SARS-like coronaviruses:

After receptor binding, a variety of cell surface or endosomal proteases cleave the SARS-CoV S glycoprotein causing massive changes in $\mathrm{S}$ structure and activating fusion-mediated entry. We will analyze all SARSr-CoV S gene sequences for appropriately conserved proteolytic cleavage sites in S2 and for the presence of potential furin cleavage sites. ... Where clear mismatches occur, we will introduce appropriate human-specific cleavage sites and evaluate growth potential in Vero cells and HAE cultures. ... We will also review deep sequence data for low abundant high risk SARSr-CoV that encode functional proteolytic cleavage sites, and if so, introduce these changes into the appropriate high abundant, low risk parental strain. ${ }^{130}$

It is clear that the researchers planned to look for the presence of furin cleavage sites at evolutionarily conserved cleavage locations in the spike gene, and if, for some reason, there was a mismatch at such conserved locations, they would introduce a human-specific cleavage site into such viruses. They also proposed to look for "functional proteolytic cleavage sites" in other high risk SARSr-CoVs and then genetically engineer such cleavage sites into low risk strains, in order to evaluate their growth potential in human airway epithelial (HAE) cell cultures.

We are traveling in all the old familiar circles. The PRRA insertion into SARS-CoV-2 created a furin cleavage site at the evolutionarily conserved $\mathrm{S} 1 / \mathrm{S} 2$ cleavage junction. It is there that many other coronaviruses have functional furin cleavage sites, including a rodent coronavirus with an RRAR furin cleavage site, collected by Shi's team from a cave in Yunnan during 2017. ${ }^{131}$

The PRRA insertion to create the PRRAR|SV cleavage site might have been inspired by the PAAR fragment found at the S1/S2 junction in another SARS-like virus from Yunnan. The strain RmYN02 was extracted from $R$. malayanus bats in 2019-the same bat species that harbored the BANAL-52 strain discovered in Laos in September $2021 .^{132}$ 
BANAL-52 is noteworthy as the first bat strain found to have an RBD that is nearly identical to the RBD found in SARS-CoV-2. Before the discovery of BANAL-52, only a pangolin-derived strain was known to harbor that particular RBD.

BANAL-52 has one further distinction. Once it had been evaluated across all of its genome, BANAL-52 displaced RaTG13 as the closest relative of SARS-CoV-2. ${ }^{133}$

As part of their collaborative arrangements, EcoHealth dispatched bat samples to the WIV for analysis. ${ }^{134}$ The WIV also gathered their own samples during field trips in Laos and from locations in Yunnan province near the Chinese border with Laos. ${ }^{135}$ The research involving these samples is discussed in a 2020 paper by Alice Latinne et al.:

Our phylogenetic analysis shows a high diversity of CoVs from bats sampled in China, with most bat genera included in this study (10/16) infected by both $\alpha$ - and $\beta$-CoVs. In our phylogenetic analysis that includes all known bat-CoVs from China, we found that SARS-CoV-2 is likely derived from a clade of viruses originating in horseshoe bats ( $R$ hinolophus spp.). The geographic location of this origin appears to be Yunnan province. However, it is important to note that: (1) our study collected and analyzed samples solely from China; (2) many sampling sites were close to the borders of Myanmar and Lao PDR; and (3) most of the bats sampled in Yunnan also occur in these countries, including $R$. affinis and $R$. malayanus, the species harboring the CoVs with highest RdRp sequence identity to SARS-CoV-2. For these reasons, we cannot rule out an origin for the clade of viruses that are progenitors of SARS-CoV-2 that is outside China, and within Myanmar, Lao PDR, Vietnam, or another Southeast Asian country. Additionally, our analysis shows that the virus RmYNO2 from $R$. malayanus, which is characterized by the insertion of multiple amino acids at the junction site of the S1 and S2 subunits of the Spike (S) protein, belongs to the same clade as both RaTG13 and SARS-CoV-2, providing further support for the natural origin of SARS-CoV-2 in Rhinolophus spp. bats in the region. ${ }^{136}$

Laotian BANAL viruses include strains designated BANAL-116 and BANAL-247. Both strains are identical to RmYNO2 at their PAA locus at the S1/S2 junction, but differ in their RBDs.

If the WIV was gathering samples inside or near Laos before the pandemic began, they may well have encountered a BANAL-52-like bat virus in co-circulation with an RmYN02-like strain exhibiting a non-functional PAAR cleavage site at the S1/S2 junction. The discovery might have prompted them to carry out an experiment along the lines suggested in the DEFUSE proposal: an experiment to turn PAAR into PRRAR and create a fully functional RRAR polybasic cleavage site.

If this counts as a conjecture, it is by no means lacking in plausibility. The PAA fragment in RmYNO2 and
BANAL-116 and -247 is coded by CCT GCA GCG codons; the PRRA insertion in SARS-CoV-2 is coded by CCT CGG CGG GCA-i.e., the codons in the SARS2 insertion coding for proline (CCT) and alanine (GCA) are identical to those found in RmYNO2 and Laotian strains.

The idea behind such work is obvious and clearly spelled out in the DARPA proposal: investigate what effect the novel furin cleavage site might have on human cells-e.g., HAE cells-or humanized mice to assess the risk of human emergence the novel bat strains might pose. Such experiments would have been a good fit for the 2019 grant from the Youth Science Fund awarded to Ben $\mathrm{Hu}$ at the WIV for investigations of the "Pathogenicity of Two New Bat SARS-Related Coronaviruses to Transgenic Mice Expressing Human ACE2 Receptor."

The decision to use CGG-CGG codons for the two arginines might have been informed by the desire to incorporate a FauI tracking beacon in the newly created furin cleavage site that would enable quick screening of whether the insertion is still present or has mutated away. ${ }^{138}$ Virologists make use of various restriction enzymes designed to recognize certain genetic sequences and cut nucleotide chains on recognition. The restriction enzyme FauI recognizes

\section{5' CCCGC \\ 3' GGGCG}

and cuts

$$
\begin{aligned}
& \text { 5'-CATG-3' } \\
& \text { 3'-GTAC- 5'. }
\end{aligned}
$$

The method using restriction enzymes for the purposes of screening for presence or absence of a particular genomic feature is termed restriction fragment length polymorphism (RFLP), ${ }^{139}$ and it has been in use for decades. ${ }^{140}$ Examples of FauI being used for RFLP analysis are well-documented in the scientific literature, ${ }^{141}$ and the WIV is known to have employed the RFLP technique in the past. ${ }^{142}$ If a researcher at the WIV had chosen to insert a novel furin cleavage site into a coronavirus, they might have also chosen to equip their insertion with a tracking beacon that could assert its continued presence via the RFLP technique. The furin cleavage site has a tendency to mutate away in vitro or in certain lab animals. ${ }^{143}$

The WIV's burgeoning interest in spike cleavage during 2019 may have been motivated by the work being undertaken by Baric's group at that time. ${ }^{144}$ In 2015, Baric and Shi published a paper on the critical importance of the furin cleavage site in MERS as a catalyst for its jump from bats to human beings. ${ }^{145}$ One of the coauthors on their paper was Shibo Jiang. Two years earlier, Jiang had reported the creation of a novel RIRR cleavage site via a 12-nucleotide insertion (CGG ATC AGG CGC), although not in a coronavirus. ${ }^{146}$ In 2020, he collaborated with Shi to develop a 
pan-coronavirus therapeutic, a fusion inhibitor peptide. ${ }^{147}$ Work on this project seemed to have been ongoing in late 2019. ${ }^{148}$ The cleavage of the spike protein is what activates fusion-mediated entry.

These observations indicate a suggestive, or even suspicious, pattern of performed or planned research at the WIV, and one that could well have produced SARS-CoV-2 with its novel furin cleavage site so uncharacteristic of SARS-like bat coronaviruses.

EcoHealth and the WIV carried out gain-of-function research both on SARS-like viruses and the vastly more deadly MERS-like viruses. The MERS outbreak in 2012 killed approximately $35 \%$ of everyone who contracted the virus. ${ }^{149}$ Between 2016 and 2019, EcoHealth and the WIV were engaged in creating novel chimeric MERS-like viruses with different RBDs spliced from other MERS-like bat viruses. ${ }^{150}$

EcoHealth's fifth-year progress report disclosed the creation of twelve novel chimeras. ${ }^{151}$ The resulting novel viruses were then tested in humanized mice and exhibited greatly increased pathogenesis.

The WIV seems to have been engaged in MERS gain-offunction research not just in collaboration with EcoHealth but separately, as well. Unpublished MERS-like reverse genetic backbones have been found in agricultural datasets from Wuhan that do not seem connected to the EcoHealth grant. ${ }^{152}$

\section{$\mathrm{T}$}

HE CURRENT SARS-CoV-2 pandemic has been, and continues to be, a public health catastrophe-the most serious in a century. Questions about the origins of COVID-19 are, at once, matters of legal, financial, and moral concern. For the moment, researchers can do no better than to hope for an inference to the best explanation; and, for the moment, the best explanation seems to be that the virus escaped from the WIV.

The WIV was the biggest transporter of viruses to Wuhan from all over Asia, including many SARS-like viruses from Laos and Yunnan. Phylogenetic analysis shows that the SARS-CoV-2 outbreak was perfectly localized in Wuhan, as all strains that have been found in other locations are descendants of the Wuhan strain. Had the virus been circulating undetected in other parts of China, virologists would have eventually noted those pre-Wuhan strains and their descendants in the phylogenetic tree. Even after sequencing over six million SARS-CoV-2 genomes, no evidence has been found of pre-Wuhan SARS-CoV-2.

Not only was the WIV the biggest reservoir of SARSlike viruses in Wuhan, if not the world, its scientists were engaged in creating novel SARS-like and MERS-like chimeras and potentially supercharging their transmissibility and pathogenicity. With these circumstances in mind, consider the following facts:

- Shi and Jiang were experts in spike protein cleavage and were working on a pan-coronavirus therapeu- tic to inhibit post-cleavage fusion of the virus with cell membranes.

- Jiang had previously created a novel furin cleavage site via a 12-nucleotide insertion, though not in a coronavirus.

- In a joint grant proposal the WIV and EcoHealth submitted to DARPA they suggested creating novel human-specific cleavage sites.

Taken together, these points make the 12-nucleotide insertion that has created a novel furin cleavage site in SARS-CoV-2-so uncharacteristic of SARS-like viruseslook extremely suspicious.

The behavior of the WIV and its scientists also raises any number of troubling questions. The viral strain RaTG13 is a case in point. First collected by the WIV in 2013, RaTG13 was sequenced in 2018, but not disclosed until after the SARS-CoV-2 outbreak. In their initial disclosure, the WIV failed to mention how or when they came to possess RaTG13, failed to indicate that it was previously called Ra4991, failed to cite their own 2016 paper first mentioning it, and seemed to imply that they only sequenced the sample after the outbreak. This does not seem like the behavior of scientists trying their utmost to establish how a Laotian or Yunnan virus came to cause an outbreak in Wuhan.

None of these points is in itself conclusive, but the circumstantial evidence is more suggestive of a lab leak than an act of nature.

There is an additional reason to take seriously the question at hand. It is prophylactic. Knowing at last that COVID-19 had its origins in the WIV would go some way toward enforcing a worldwide ban on gain-of-function research-research that is almost as useless as it is dangerous.

Yuri Deigin is a biotech entrepreneur with a background in drug discovery and development.

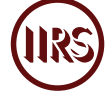

1. Office of the Director of National Intelligence, "Unclassified Summary of Assessment on COVID-19 Origins," August 27,2021 . The full report was released several months later: Office of the Director of National Intelligence, "Declassified Assessment on COVID-19 Origins," October 29, 2021.

2. Office of the Director of National Intelligence, "Unclassified Summary of Assessment on COVID-19 Origins," August 27, 2021, 1.

3. Julian Barnes, "Origin of Virus May Remain Murky, U.S. Intelligence Agencies Say," New York Times, November 1, 2021.

4. Office of the Director of National Intelligence, "Unclassified Summary of Assessment on COVID-19 Origins," August 27, 
2021, 1. They had a point. Virologists now agree that the 1977 H1N1 pandemic was most likely caused by an insufficiently attenuated vaccine leaked from a Chinese laboratory. See Joel Wertheim, "The Re-Emergence of H1N1 Influenza Virus in 1977: A Cautionary Tale for Estimating Divergence Times Using Biologically Unrealistic Sampling Dates," PLOS ONE 5, no. 6 (2010), doi:10.1371/journal.pone.0011184.

For decades, the 1979 anthrax outbreak in Sverdlovsk, USSR, was believed to be zoonotic. The USSR even invited international experts to interview Soviet scientists about the outbreak. The scientific consensus might have remained untroubled were it not for Boris Yeltsin's shocking admission in 1992 that he helped cover up the laboratory leak that had caused it. See R. Jeffrey Smith, "Yeltsin Blames '79 Anthrax on Germ Warfare Efforts," The Washington Post, June 16, 1992.

5. World Health Organization, "WHO Coronavirus (COVID19) Dashboard."

6. Wertheim, "The Re-Emergence of H1N1 Influenza Virus."

7. Vincent Cheng et al., "Severe Acute Respiratory Syndrome Coronavirus as an Agent of Emerging and Reemerging Infection," Clinical Microbiology Reviews 20, no. 4 (2007): 683, doi:10.1128/CMR.00023-07.

8. Wikipedia, "Horseshoe Bat."

It is worth noting that the bats deemed the origin for the 2002 outbreak of SARS had a close bat virus relative, discovered in 2011 in Yunnan horseshoe bats by the head of coronavirus research at the Wuhan Institute of Virology, Shi Zhengli. Jane Qiu, “How China's ‘Bat Woman' Hunted Down Viruses from SARS to the New Coronavirus," Scientific American, June 1, 2020. Designated as Rs3367, the bat virus shares $96 \%$ of its amino acid sequence with SARS. It is believed that the original bat virus first jumped to palm civets, the intermediate host, and then jumped to humans in Guangdong. The palm civet SARS progenitor strain shared over $99.8 \%$ of its genome with the human SARS strain identified in Guangdong. Yi Guan et al., "Isolation and Characterization of Viruses Related to the SARS Coronavirus from Animals in Southern China," Science 302, no. 5,643 (2003): 276-78, doi:10.1126/science.1087139.

9. Kristian Andersen et al., "The Proximal Origin of SARSCoV-2" (preprint), virological.org (February 17, 2020); and Kristian Andersen et al., "The Proximal Origin of SARSCoV-2," Nature Medicine 26 (March 17, 2020): 450-52, doi:10.1038/s41591-020-0820-9.

The paper became one of the most widely cited papers in all of virology, eliciting more than 2,700 citations, and also earned the third spot out of almost 20 million scientific papers tracked by the Altmetric score, which tallies up references to scientific publications in press and social media. "The Proximal Origin of SARS-CoV-2 Overview of Attention for Article Published in Nature Medicine, March 2020," Altmetric.

10. One of the most striking aspects of the Andersen et al. papers concerns the significance of the novel furin cleavage site insertion. Just days before publishing the paper, Andersen remarked that the insertion "looks engineered" during an email exchange with Anthony Fauci, director of the National Institute of Allergy and Infectious Diseases. In their paper, Andersen et al. do not express any surprise over the furin cleavage site. Instead they state that, "the acquisition of both the polybasic cleavage site and predicted O-linked glycans also argues against culture-based scenarios."

Subsequent culture-based passaging of SARS-CoV-2 in the presence of antibodies reveal that novel glycan sequons can arise in vitro. See Emanuele Andreano et al., "SARS-CoV-2 Escape from a Highly Neutralizing COVID-19 Convalescent Plasma," Proceedings of the National Academy of Sciences 118, no. 36 (2021), doi:10.1073/pnas.2103154118. The posited presence of $\mathrm{O}$-linked glycans near the furin cleavage site was later experimentally shown to be false, as Andersen himself publicly admitted. Rosanna Segretto, Twitter post, May 10, 2021, 1:06 AM.

Finally, Andersen et al. remark,

[S]ubsequent generation of a polybasic cleavage site would have then required repeated passage in cell culture or animals with ACE2 receptors similar to those of humans, but such work has also not previously been described.

It is now well documented that the WIV used humanized mice and passaged viruses in humanized mice or civets. Moreover, a novel polybasic cleavage site can easily be generated through genetic engineering. Rowan Jacobsen, "Inside the Risky Bat-Virus Engineering that Links America to Wuhan," MIT Technology Review, June 29, 2021; Jon Cohen, "Wuhan Coronavirus Hunter Shi Zhengli Speaks Out," Science 369, no. 6,503 (2020): 487-88, doi:10.1126/ science.369.6503.487; and Zhengli Shi, "Reply to Science Magazine," July 15, 2020. The latter reference contains the responses from Shi that appeared in Cohen's interview.

11. Charles Calisher et al., "Statement in Support of the Scientists, Public Health Professionals, and Medical Professionals of China Combatting COVID-19," The Lancet 395, no. 10,226 (2020): E42-43, doi:10.1016/S0140-6736(20)30418-9.

12. Betsy McKay, "NIH Presses U.S. Nonprofit for Information on Wuhan Virology Lab,” Wall Street Journal, August 19, 2020.*

13. Jacobsen, "Inside the Risky Bat-Virus Engineering."

14. Editors of the Lancet, "Addendum: Competing Interests and the Origins of SARS-CoV-2," The Lancet 397, no. 10,293 (2021): 2,449-50, doi:10.1016/S0140-6736(21)01377-5.

15. Simone McCarthy, "WHO Names Line-up for International Team looking into Coronavirus Origins," Yahoo! News, November 25, 2020. The reporting notes that Daszak was "known for his research into SARS-like bat coronaviruses in southeastern China and president of US group EcoHealth Alliance. Daszak is also heading a separate task force looking into the virus origins under The Lancet scientific journal's COVID-19 Commission."

16. World Health Organization, WHO-Convened Global Study of Origins of SARS-CoV-2: China Part; Joint WHO-China Study 14 January-10 February 2021 (March 30, 2021), 9, 120. 
17. WHO-Convened Global Study of Origins, 9, 115.

18. WHO-Convened Global Study of Origins, 119.

19. Peter Ben Embarek quoted in Adam Taylor, Emily Rauhala, and Martin Selsoe Sorensen, "In New Documentary, WHO Scientist Says Chinese Officials Pressured Investigation to Drop Lab-Leak Hypothesis,” Washington Post, August 12, 2021.

20. Ben Embarek quoted in Taylor, Rauhala, and Sorensen, "WHO Scientist Says Chinese Officials Pressured Investigation."

21. Taylor, Rauhala, and Sorensen, "WHO Scientist Says Chinese Officials Pressured Investigation.”

22. The Associated Press, "The WHO's Chief Says It Was Premature to Rule out a Lab Leak as the Pandemic's Origin," NPR, July 15, 2021.

23. "WHO Calls for Audit of Chinese Labs Where COVID-19 Was First Identified," Euronews, July 17, 2021.

24. The Associated Press, "WHO's Chief Says It Was Premature to Rule Out a Lab Leak," NPR, July 15, 2021.

25. See the studies described in WHO-Convened Global Study of Origins, 8; and Wan-Ting He et al., "Total Virome Characterizations of Game Animals in China Reveals a Spectrum of Emerging Viral Pathogens," bioRxiv (2021), doi:10.1101/2021.11.10.467646.

26. Anthony Fauci, Gary Nabel, and Francis Collins, "A Flu Virus Risk Worth Taking,” Washington Post, December 30, 2011.

27. Anthony Fauci, "Research on Highly Pathogenic H5N1 Influenza Virus: The Way Forward," mBio 3, no. 5 (2012), doi:10.1128/mBio.00359-12.

28. Fauci, "Research on Highly Pathogenic H5N1."

29. Remarks cited in David Willman and Madison Muller, "A Science in the Shadows," Washington Post, August 26, 2021. Fauci's complete presentation and these remarks can be viewed on YouTube. National Institutes of Health (NIH), "Gain-of-Function Research on HPAI H5N1 Viruses: Welcome and Introductory Remarks," YouTube video, March 20, 2013, 32:56.

30. Vineet Menachery et al., "A SARS-Like Cluster of Circulating Bat Coronaviruses Shows Potential for Human Emergence," Nature Medicine 21 (2015): 1,508-13, doi:10.1038/nm.3985.

31. Willman and Muller, "A Science in the Shadows."

32. Willman and Muller, "A Science in the Shadows."

33. Willman and Muller, "A Science in the Shadows"; Jacobsen, "Inside the Risky Bat-Virus Engineering."

34. It has been claimed that this announcement occurred without proper consultation. A report in The Australian affirmed that, "[m]ultiple Trump administration officials told [the paper] Dr Fauci had not raised the issue of restarting the research funding with senior figures in the White House." One official was quoted as saying that "It kind of just got rammed through." The official continued: "I think there's truth in the narrative that the (National Security Council) staff, the president, the White House chief-of-staff, those people were in the dark that he was switching back on the research.” Sharri Markson, "Anthony Fauci Backed Virus Experiments 'Despite Pandemic Risk'," The Australian, May 28, 2021.
35. Ben $\mathrm{Hu}$ et al., "Discovery of a Rich Gene Pool of Bat SARS-Related Coronaviruses Provides New Insights into the Origin of SARS Coronavirus," PLOS Pathogens 13, no. 11 (2017), doi:10.1371/journal.ppat.1006698.

36. "Understanding the Risk of Bat Coronavirus Emergence," NIH RePORTER, Project Number 2R01AI110964-06, Project Leader Peter Daszak (2019).

37. "Dr. Fauci Testifies at Senate Hearing on Covid-19 Response | NBC News," YouTube video, May 11, 2021, 2:38:35.

38. Email from Anthony Fauci to Hugh Auchincloss, February 1, 2020, released under the Freedom of Information Act.

39. Emails between Anthony Fauci and Kristian Andersen, January 31, 2020, released under the Freedom of Information Act.

40. Alison Young, "Opinion: 'I Remember It Very Well': Dr. Fauci Describes a Secret 2020 Meeting to Talk About COVID Origins," USA Today, June 17, 2021.

41. Young, "Opinion: 'I Remember It Very Well',

42. Young, "Opinion: 'I Remember It Very Well'."

43. Andersen et al., "The Proximal Origin of SARS-CoV-2."

44. The emails were obtained under the FOIA in response to a lawsuit filed by Buzzfeed News and the Washington Post. Natalie Bettendorf and Jason Leopold, "Anthony Fauci's Emails Reveal the Pressure That Fell on One Man," Buzzfeed News, June 2, 2021; and Christina Maxouris and Paul LeBlanc, "Thousands of Fauci's Emails Were Released under the Freedom of Information Act," CNN, June 3, 2021.

45. Yuri Deigin, "Response of Dr. Kristian G. Andersen to Questions Relating to His Email to Dr. Fauci Recently Released under FOIA," Medium (Yuri Deigin), June 4, 2021.

46. Archive.Today version of Kristian Anderson, Twitter post, January 23, 2020, 11:11 PM (since deleted); and Lab Leak, Twitter post, June 4, 2021.

47. Anders Anglesey, "Scientist Who Warned Fauci COVID Could Be 'Engineered' Deletes Twitter Account," Newsweek, June 7, 2021; and Ian Birrell, "Did Scientists Stifle the LabLeak Theory?, UnHerd, July 22, 2021.

48. Jeremy Farrar and Anjana Ahuja, Spike: The Virus vs. The People - The Inside Story (London: Profile, 2022).

49. Birrell, "Did Scientists Stifle the Lab-Leak Theory?"

50. Email from Kristian Andersen to Peter Daszak, February 4, 2020, released under the Freedom of Information Act; and Calisher et al., "Statement in Support of the Scientists."

51. Email from Jeremy Farrar to Anthony Fauci and Francis Collins, February 5, 2020, released under the Freedom of Information Act; to view the email, see CDommasch, Twitter post, January 15, 2022, 12:52 PM.

52. Emails between Peter Daszak and Ralph Baric, February 6, 2020, released under the Freedom of Information Act.

53. Lucy van Dorp et al., "Emergence of Genomic Diversity and Recurrent Mutations in SARS-CoV-2," Infection, Genetics and Evolution 83 (2020), doi:10.1016/j.meegid.2020.104351.

54. Guan et al., "Isolation and Characterization of Viruses."

55. Michael Worobey, "Dissecting the Early COVID-19 Cases in Wuhan,” Science 374, no. 6,572 (2021), doi:10.1126/science. abm4454. His story was picked up by other outlets: Jane Qiu, “This Scientist Now Believes Covid Started in Wuhan's 
Wet Market. Here's Why," MIT Technology Review, November 19, 2021.

56. Worobey quoted in Daniel Stolte, "Evidence Points to Animal Market, Not Lab, as Epicenter of Pandemic," University of Arizona News, November 18, 2021.

57. Linda Lew, "Chinese Scientist Hits Back at Wuhan Market Coronavirus Origin Paper," South China Morning Post, December 11, 2021; and Yuri Deigin, Twitter post, December 12, 2021, 3:22 PM.

58. Worobey, "Dissecting the Early COVID-19 Cases in Wuhan."

59. He et al., "Total Virome Characterizations of Game Animals."

60. Worobey, "Dissecting the Early COVID-19 Cases in Wuhan."

61. Jesse Bloom, "Recovery of Deleted Deep Sequencing Data Sheds More Light on the Early Wuhan SARS-CoV-2 Epidemic," Molecular Biology and Evolution (2021): msab246, doi:10.1093/molbev/msab246.

62. Bloom, "Recovery of Deleted Deep Sequencing Data"; and Sudhir Kumar et al., "An Evolutionary Portrait of the Progenitor SARS-CoV-2 and Its Dominant Offshoots in COVID-19 Pandemic," Molecular Biology and Evolution 38, no. 8 (2021): 3,046-59, doi:10.1093/molbev/msab118.

63. Ning Wang et al., "Serological Evidence of Bat SARS-Related Coronavirus Infection in Humans, China," Virologica Sinica 33, no. 1 (2018): 104-107, doi:10.1007/s12250-018-0012-7.

64. Peter Daszak, Twitter post, April 16, 2020, 4:30 PM.

65. Qiu, "How China's 'Bat Woman' Hunted Down Viruses."

66. "Understanding the Risk of Bat Coronavirus Emergence," NIH RePORTER.

67. "Understanding the Risk of Bat Coronavirus Emergence," NIH RePORTER.

68. Meredith Wadman and Jon Cohen, "NIH's Axing of Bat Coronavirus Grant a 'Horrible Precedent' and Might Break Rules, Critics Say," Science, April 30, 2020; Sarah Owermohle, "Trump Cuts U.S. Research on Bat-Human Virus Transmission over China Ties,” Politico, April 27, 2020; and EcoHealth Alliance, "Regarding NIH Termination of Coronavirus Research Funding."

69. Wadman and Cohen, "NIH's Axing of Bat Coronavirus Grant"; and Nurith Aizenman, "Why the U.S. Government Stopped Funding a Research Project on Bats and Coronaviruses," NPR, April 29, 2020.

70. USASPENDING.gov, "Project Grant FAIN R01AI11964." See the Sub-Awards section of the Award History for details of the funds distributed to WIV. The services provided are summarized as "Conduct high-quality testing, sequencing, and analyses of field samples; maintenance of cold-chains from field to lab; ensuring quality control of sample storage and testing; collaborating on scientific publications and programmatic reporting."

71. Jie Cui, Fang Li, and Zheng-Li Shi, "Origin and Evolution of Pathogenic Coronaviruses,” Nature Reviews Microbiology 17, no. 3 (2019): 181-92, doi:10.1038/s41579-018-0118-9.

72. Yuri Deigin, Twitter post, May 23, 2020, 8:06 PM; and Vincent Racaniello, "TWiV 615: Peter Daszak of EcoHealth Alliance,” YouTube video, May 29, 2020, 30:00.
73. MedSci, “两株新型蝙蝠SARS相关冠状病毒对表达人ACE2 的转基因小鼠的致病性研究-国家自然科学基金摘要查 询-MedSci.cn. (Pathogenicity of Two Novel Bat SARS-Associated Coronaviruses in Transgenic Mice Expressing Human ACE2-National Natural Science Foundation of China-MedSci.cn)."

74. Xing-Yi Ge, Ben Hu, and Zheng-Li Shi, "Bat Coronaviruses" in Bats and Viruses: A New Frontier of Emerging Infectious Diseases, ed. Lin-Fa Wang and Christopher Cowled (Hoboken, NJ: John Wiley \& Sons, 2015), 127-55.

75. “Coronaviruses: The Next Disease X?," The Native Antigen Company, November 5, 2019; Menachery et al., "A SARSLike Cluster of Circulating Bat Coronaviruses"; Kevin Loria, "The World Health Organisation Is Worried about Disease $\mathrm{X}$ and You Should Be Too," World Economic Forum, March 15, 2018; and Simone McCarthy et al., "How Disease X, the Epidemic-in-Waiting, Erupted in China," South China Morning Post, February 27, 2020.

76. Shibo Jiang and Zheng-Li Shi, "The First Disease X Is Caused by a Highly Transmissible Acute Respiratory Syndrome Coronavirus," Virologica Sinica 35, no. 3 (2020): 263-65, doi:10.1007/s12250-020-00206-5.

77. Yuri Deigin and Rossana Segreto, "SARS-CoV-2's Claimed Natural Origin Is Undermined by Issues with Genome Sequences of Its Relative Strains," BioEssays 43, no. 7 (2021): e2100015, doi:10.1002/bies.202100015.

78. In China specifically, they did so as early as 2006 and as recently as 2019. See Kathryn Follis, Joanne York, and Jack Nunberg, "Furin Cleavage of the SARS Coronavirus Spike Glycoprotein Enhances Cell-Cell Fusion but Does Not Affect Virion Entry," Virology 350, no. 2 (2006): 358-69, doi:10.1016/j.virol.2006.02.003; and Jinlong Cheng et al., "The S2 Subunit of QX-type Infectious Bronchitis Coronavirus Spike Protein Is an Essential Determinant of Neurotropism," Viruses 11, no. 10 (2019): 972, doi:10.3390/ v11100972.

79. Bill Gallaher, "Analysis of Wuhan Coronavirus: Deja Vu," virological.org, January 2020; and Wei Zhang et al., "A Furin Cleavage Site Was Discovered in the S Protein of the 2019 Novel Coronavirus," Chinese Journal of Bioinformatics (in Chinese) 18, no. 2 (2020): 103-108, doi:10.12113/202002001. An even more peculiar feature is dependent on the presence of CGG codons in the insertion. The furin cleavage site has a tendency to mutate away in culture or in certain lab animals. The CGG codons in the insertion allow the concurrent creation of a FauI restriction enzyme digestion site, which can be used for quick and efficient viral colony screening to check if the furin cleavage site is still there. The method of using restriction sites to screen for the presence or absence of a particular genomic feature is called restriction fragment length polymorphism (RFLP). It has been in use for decades. Examples of using FauI for RFLP analysis are well documented in scientific literature, and the WIV itself has been known to employ the RFLP technique before. If someone at the WIV chose to insert a furin cleavage site into a coronavirus, it is plausible they would also equip their inser- 
tion with a "tracking beacon" to be able to quickly assert its continued presence via the RFLP technique.

80. Kamal Shokeen et al., "Insight towards the Effect of the Multibasic Cleavage Site of SARS-CoV-2 Spike Protein on Cellular Proteases," bioRxiv (2020), doi:10.1101/2020.04.25.061507; Jean Kaoru Millet and Gary Whittaker, "Host Cell Proteases: Critical Determinants of Coronavirus Tropism and Pathogenesis," Virus Research 202 (2014): 120-34, doi:10.1016/j. virusres.2014.11.021; and Thomas Peacock et al., "The Furin Cleavage Site in the SARS-CoV-2 Spike Protein Is Required for Transmission in Ferrets," Nature Microbiology 6 (2021): 899-909, doi:10.1038/s41564-021-00908-w.

81. Peng Zhou et al., "A Pneumonia Outbreak Associated with a New Coronavirus of Probable Bat Origin," Nature 579, (2020): 270-73, doi:10.1038/s41586-020-2012-7; and Shibo Jiang, Lanying Du, and Zhengli Shi, "An Emerging Coronavirus Causing Pneumonia outbreak in Wuhan, China: Calling for Developing Therapeutic and Prophylactic Strategies," Emerging Microbes $\mathcal{E}$ Infections 9, no. 1 (2020): 275-77, doi:1 $0.1080 / 22221751.2020 .1723441$.

82. See the discussion concerning RaTG13 in Zhou et al., "A Pneumonia Outbreak":

Phylogenetic analysis of the full-length genome and the gene sequences of $R d R p$ and spike (S) showed thatfor all sequences-RaTG13 is the closest relative of 2019-nCoV and they form a distinct lineage from other SARSr-CoVs.

83. Another possibility is that the ancestral strain already had TCT rather than TCA for the serine codon preceding the insertion, and the insertion is fully in frame: CCT CGG CGG GCA [PRRA].

84. Yuri Deigin and Rossana Segretto, "The Genetic Structure of SARS-CoV-2 is Consistent with Both Natural or Laboratory Origin: Response to Tyshkovskiy and Panchin (10.1002/ bies.202000325)," BioEssays 43, no. 9 (2021): e2100137, doi:10.1002/bies.202100137.

85. Gao Yu et al., "How Early Signs of the Coronavirus Were Spotted, Spread and Throttled in China," The Straits Times, February 28, 2020.

86. Peng Zhou et al., "Discovery of a Novel Coronavirus Associated with the Recent Pneumonia Outbreak in Humans and Its Potential Bat Origin," bioRxiv (2020); Zhou et al., "A Pneumonia Outbreak."

87. Zhou et al., "A Pneumonia Outbreak."

88. “amplicon_sequences of RaTG13 (SRR11806578)," NCBI Sequence Read Archive.

89. This is confirmed by Shi in her answer to question (7) in Shi, "Reply to Science Magazine." Further confirmation of the chronology was provided in the following paper: Peng Zhou et al., "Addendum: A Pneumonia Outbreak Associated with a New Coronavirus of Probable Bat Origin," Nature 588, E6 (2020), doi:10.1038/s41586-020-2951-z.

90. Monali Rahalkar and Rahul Bahulikar, "Lethal Pneumonia Cases in Mojiang Miners (2012) and the Mineshaft Could
Provide Important Clues to the Origin of SARS-CoV-2," Frontiers in Public Health 8:581569 (2020), doi:10.3389/ fpubh.2020.581569.

91. Rossana Segreto and Yuri Deigin, "The Genetic Structure of SARS-CoV-2 Does Not Rule Out a Laboratory Origin,” BioEssays 43, no. 3 (2020), doi:10.1002/bies.202000240.

92. Zhou et al., "Addendum."

93. Xing-Yi Ge et al., "Coexistence of Multiple Coronaviruses in Several Bat Colonies in an Abandoned Mineshaft," Virologica Sinica 31 (2016): 31-40, doi:10.1007/s12250-016-3713-9.

94. "Rhinolophus Bat Coronavirus BtCoV/4991 RNA-Dependent RNA polymerase (RdRp) Gene, Partial cds," GenBank: KP876546.1

95. Zhou et al., "A Pneumonia Outbreak."

96. Jiang, Du, and Shi, "An Emerging Coronavirus." This paper was submitted on January 20, 2020, three days before the preprint by Zhou et al., "Discovery of a Novel Coronavirus."

97. The initial submission QHR63260.1 was subsequently corrected by QHR63260.2 that saw the first nine amino acids (mflltkrt) of the spike protein deleted.

98. Jiang, Du, and Shi, "An Emerging Coronavirus."

99. Fabian Zech et al., "Spike Residue 403 Affects Binding of Coronavirus Spikes to Human ACE2," Nature Communications 12, no. 6,855 (2021), doi:10.1038/s41467-021-27180-0:

Both WT SARS-CoV-2 S and (to a lesser extent) R403T SARS-CoV-2 S proteins were also capable of using bat (Rhinolophus affinis) ACE2 for viral entry although the overall infection rates were low. In contrast, the RaTG13 $S$ proteins were unable to use bat ACE2 for infection suggesting that RaTG13 might use an alternative receptor for infection of bat cells [emphasis added].

100. The WIV clearly knew how to adapt human viruses to rodent animal models, as they had humanized mice in their lab. Ren-Di Jiang et al., "Pathogenesis of SARS-CoV-2 in Transgenic Mice Expressing Human Angiotensin-Converting Enzyme 2," Cell 182, no. 1 (2020): 50-58.E8, doi:10.1016/j. cell.2020.05.027.

101. Ning Wang, "Serological Cross-Reactivity Analysis of Coronavirus Based on Nucleocapsid Proteins" (MSc thesis, Wuhan Institute of Virology, May 2014).

102. Ge et al., "Coexistence of Multiple Coronaviruses."

103. "Rhinolophus Bat Coronavirus BtCoV/4991 RNA-Dependent RNA Polymerase (RdRp) Gene, Partial CDS,” GenBank: KP876546.1.

104. Yu Ping, "Geographic Evolution of Bat SARS-related Coronaviruses" (MSc thesis, Wuhan Institute of Virology, June 2019).

105. The Q\&A was published alongside an article on Shi that drew upon this material. Cohen, "Wuhan Coronavirus Hunter Shi Zhengli Speaks Out.”

106. The explanation appears on page 7 of Shi, "Reply to Science Magazine."

107. Deigin and Segreto, "SARS-CoV-2's Claimed Natural Origin Is Undermined." 
108. See page 7 in Shi, "Reply to Science Magazine."

109. David Cyranoski, "Chinese Institutes Investigate Pathogen Outbreaks in Lab Workers," Nature, December 17, 2019; and Shah Marzia Mahjabin Lina, Mohana Priya Kunasekaran, and Aye Moa, "Brucellosis Outbreak in China, 2019," Global Biosecurity 3, no. 1 (2021), doi:10.31646/gbio.108.

110. Wertheim, "The Re-Emergence of H1N1 Influenza Virus."

111. Peter Palese, "Influenza: Old and New Threats," Nature Medicine 10 (2004): S82-S87, doi:10.1038/nm1141.

112. See Table 1, "Influenza Pandemics Since the 20th Century," in Martin Michaelis, Hans Wilhem Doerr, and Jindrich Cinatl Jr., "Novel Swine-Origin Influenza A Virus in Humans: Another Pandemic Knocking at the Door," Medical Microbiology and Immunology 198, no. 3 (2009): 175-83, doi:10.1007/s00430-009-0118-5.

113. Wikipedia, "Sverdlovsk Anthrax Leak."

114. Poh Lian Lim et al., "Laboratory-Acquired Severe Acute Respiratory Syndrome," New England Journal of Medicine 350 (2004): 1,740-45, doi:10.1056/NEJMoa032565; "SARS Case Confirmed in Taiwan,” Wired, December 17, 2003; and Robert Walgate, "SARS Escaped Beijing Lab Twice," The Scientist, April 25, 2004.

115. Josh Rogin, "State Department Cables Warned of Safety Issues at Wuhan Lab Studying Bat Coronaviruses," The Washington Post, April 14, 2020.

116. Rogin, "State Department Cables Warned of Safety Issues."

117. "China Orders Safety Overhaul at University Labs," Xinhua Net, January 26, 2019.

118. Sainath Suryanarayana, "Senior Chinese Scientist Acquired SARS-CoV-2 in Lab Infection Accident, Virologist Says," U.S. Right to Know, August 5, 2021.

119. Matt Field, "A Lab Assistant Involved in Covid-19 Research in Taiwan Exposed 110 People after Becoming Infected at Work," Bulletin of the Atomic Scientists, January 25, 2022.

120. “病毒资源 (Virus Resources)” archived at web.archive.org on October 23, 2017.

Another notable change was the deletion of the WIV's viral database, which was once publicly available. The database originally contained $61.5 \mathrm{Mb}$ of data, but when I tried to download it again in May 2020, it was no longer available. Soon after, the database description page was also taken down, but its archived copy is still available. In a December 2020 interview with the $B B C$, Shi was asked why the the database had been deleted. She replied that it was removed for security reasons. Yuri Deigin, Twitter post, May 11, 2020, 7:02 PM; Tang Yijie et al., "Bat and Rodent-Borne Viral Pathogen Database," CSData 4, no. 4 (2019), doi:10.11922/ csdata.2019.0018.zh, archived at web.archive.org on May 29, 2020; and John Sudworth, "Covid: Wuhan Scientist Would 'Welcome' Visit Probing Lab Leak Theory,' BBC News, December 21, 2020.

121. "Biosafety in Microbiological and Biomedical Laboratories," 6th edn., Centers for Disease Control and Prevention, National Institutes of Health, June 2020, 32.

122. Shi, "Reply to Science Magazine," 1.

123. Jacobsen, "Inside the Risky Bat-Virus Engineering."
124. Jacobsen, "Inside the Risky Bat-Virus Engineering." 125. Jacobsen, "Inside the Risky Bat-Virus Engineering." 126. Jacobsen, "Inside the Risky Bat-Virus Engineering."

127. Michael Gordon, Warren Strobel, and Drew Hinshaw, "Intelligence on Sick Staff at Wuhan Lab Fuels Debate on Covid-19 Origin,” Wall Street Journal, May 23, 2021; and Office of the Spokesperson, "Fact Sheet: Activity at the Wuhan Institute of Virology,” US Department of State, January 15, 2021.

128. Josephine Ma, "Coronavirus: China's First Confirmed COVID-19 Case Traced Back to November 17," South China Morning Post, March 13, 2020. There were other reports of expats living in Wuhan having contracted COVID-19 published in November 2019, e.g., "Man 'Who Had Coronavirus' Says He is Isolated in Wuhan," BBC News, February 4, 2020.

129. Sharon Lerner and Maia Hibbett, "Leaked Grant Proposal Details High-Risk Coronavirus Research," The Intercept, September 23, 2021.

130. Project DEFUSE: Defusing the Threat of Bat-Borne Coronaviruses (grant proposal HR001118S0017-PREEMPT-PA-001, submitted by EcoHealth Alliance to DARPA, March 27, 2018), 11.

131. Xing-Yi Ge et al., "Detection of Alpha- and Betacoronaviruses in Rodents from Yunnan, China," Virology Journal 14, no. 98 (2017), doi:10.1186/s12985-017-0766-9; and Ge et al., "Coexistence of Multiple Coronaviruses."

Cross-species coronavirus transmission, including between bats and rodents, seems to have been of particular interest to Shi, as evident by the description of the WIV viral database with "20,000 pieces of animal samples and virus data from bats and rodents," which shi curated personally and that contained the keywords "cross-species transmission." Shi deleted those keywords on December 30, 2019. Yuri Deigin, Twitter post, May 14, 2020, 11:00 AM.

132. Sarah Temmam et al., "Coronaviruses with a SARS-CoV-2Like Receptor-Binding Domain Allowing ACE2-Mediated Entry into Human Cells Isolated from Bats of Indochinese Peninsula," Nature Portfolio (In Review) (2021), doi:10.21203/ rs.3.rs-871965/v1.

133. RmYNO2 is closer to SARS-CoV-2 than RaTG13 only if the receptor-binding domain is excluded from the comparison.

134. "Gain of Function Communications between EcoHealth Alliance and NIAID Obtained by the White Coat Waste Project as the Result of a Freedom of Information Act Lawsuit," Scribd, uploaded by Andrew Kerr, 60.

135. Francisco de Asis, Twitter post, November 12, 2021, 6:16 PM; "Rousettus Bat Coronavirus HKU9 Isolate 7554-2 RNA-Dependent RNA Polymerase (RdRp) Gene, Partial cds," GenBank: MN312670.1.

136. Alice Latinne et al., "Origin and Cross-Species Transmission of Bat Coronaviruses in China," Nature Communications 11, no. 4,235 (2020), doi:10.1038/s41467-020-17687-3.

137. MedSci，“两株新型蝙蝠SARS相关冠状病毒对表达人ACE2 的转基因小鼠的致病性研究-国家自然科学基金摘要查 询-MedSci.cn. (Pathogenicity of Two Novel Bat SARS-Associated Coronaviruses)."

138. Segreto and Deigin, "The Genetic Structure of SARS-CoV-2.” 
139. Shiv Shankhar Kaundun et al., "Derived Polymorphic Amplified Cleaved Sequence (dPACS): A Novel PCR-RFLP Procedure for Detecting Known Single Nucleotide and Deletion-Insertion Polymorphisms," International Journal of Molecular Sciences 20, no. 13 (2019), doi:10.3390/ ijms20133193.

140. Sikandar Khan et al., "The Human XPC DNA Repair Gene: Arrangement, Splice Site Information Content and Influence of a Single Nucleotide Polymorphism in a Splice Acceptor Site on Alternative Splicing and Function," Nucleic Acids Research 30, no. 16 (2002): 3,624-31, doi: 10.1093/nar/gkf469.

141. Nathan Havill, Stephen Gaimari, and Adalgisa Caccone, "Cryptic East-West Divergence and Molecular Diagnostics for Two Species of Silver Flies (Diptera: Chamaemyiidae: Leucopis) from North America Being Evaluated for Biological Control of Hemlock Woolly Adelgid," Biological Control 121 (2018): 23-29, doi:10.1016/j.biocontrol.2018.02.004; Mirosława Cieślińska, "Genetic Diversity of Seven Strawberry mottle virus Isolates in Poland," The Plant Pathology Journal 35, no. 4 (2019): 389-92, doi:10.5423/PPJ. NT.12.2018.0306; and Jing Zhang et al., "A Loss-of-Function Mutation in the Integrin Alpha L (Itgal) Gene Contributes to Susceptibility to Salmonella enterica Serovar Typhimurium Infection in Collaborative Cross Strain CC042," Infection and Immunity 88, no. 1 (2019), doi:10.1128/IAI.00656-19.

142. Lei-Ping Zeng et al., "Bat Severe Acute Respiratory Syndrome-Like Coronavirus WIV1 Encodes an Extra Accessory Protein, ORFX, Involved in Modulation of the Host Immune Response," Journal of Virology 90, no. 14 (2016), doi:10.1128/ JVI.03079-15.

143. Michito Sasaki et al., "SARS-CoV-2 Variants with Mutations at the $\mathrm{S} 1 / \mathrm{S} 2$ Cleavage Site Are Generated in vitro during Propagation in TMPRSS2-Deficient Cells," PLOS Pathogens (2021), doi:10.1371/journal.ppat.1009233; Zhe Liu et al., "Identification of Common Deletions in the Spike Protein of Severe Acute Respiratory Syndrome Coronavirus 2," Journal of Virology 94, no. 17 (2020): e00790-20, doi:10.1128/ JVI.00790-20; and Siu-Ying Lau et al., "Attenuated SARSCoV-2 Variants with Deletions at the S1/S2 Junction," Emerging Microbes \& Infections 9, no. 1 (2020): 837-42, doi:1 0.1080/22221751.2020.1756700.

144. Veneet Menachery et al., "Trypsin Treatment Unlocks Barrier for Zoonotic Coronaviruses Infection,” bioRxiv (2019), doi:10.1101/768663; later published in Journal of Virology 94, no. 5 (2020), doi:10.1128/JVI.01774-19.

145. Yang Yang et al., "Two Mutations Were Critical for Bat-toHuman Transmission of Middle East Respiratory Syndrome Coronavirus," Journal of Virology 89, no. 17 (2015): 9,119-23, doi:10.1128/JVI.01279-15.

146. Yuanping Zhou et al., "Simultaneous Expression of Displayed and Secreted Antibodies for Antibody Screen," PLOS ONE 8, no. 11 (2013): e80005, doi:10.1371/journal. pone.0080005.

147. Shuai Xia et al., "Inhibition of SARS-CoV-2 (Previously 2019-nCoV) Infection by a Highly Potent Pan-Coronavirus Fusion Inhibitor Targeting Its Spike Protein that Harbors a High Capacity to Mediate Membrane Fusion," Cell Research 30 (2020): 343-55, doi:10.1038/s41422-020-0305-x.

148. Shuai Xia et al., "A Pan-Coronavirus Fusion Inhibitor Targeting the HR1 Domain of Human Coronavirus Spike," Science Advances 5, no. 4 (2019): eaav4580, doi:10.1126/ sciadv.aav 4580 .

149. World Health Organization, "Middle East Respiratory Syndrome Coronoavirus (MERS-CoV)."

150. "We constructed the full-length infectious clone of MERS$\mathrm{CoV}$, and replaced the RBD of MERS-CoV with the RBDs of various strains of HKU4-related coronaviruses previously identified in bats from different provinces in southern China." Quoted in Sharon Lerner and Maia Hibbett, "EcoHealth Alliance Conducted Risky Experiments on MERS Virus in China," The Intercept, October 21, 2021.

151. "The full-length infectious cDNA clone of MERS-CoV has been successfully constructed. The full-length $\mathrm{S}$ gene of 12 different novel bat MERS-related coronaviruses have been amplified and cloned into the T-vectors." "Understanding the Risk of Bat Coronavirus Emergence" (Grant Number 5R01AI110964-05, report submitted by EcoHealth Alliance to the National Institute of Allergy and Infectious Diseases, August 3, 2021).

152. Adrian Jones, "Risky MERSr-CoV Research in Wuhan," Medium, November 5, 2021. These details were uncovered by DRASTIC, a team of scientists and researchers formed in 2020 to investigate the origins of COVID-19.

DOI: $10.37282 / 991819.22 .13$ 